\title{
UMA POSSÍVEL ESTRUTURA DE IMPACTO DE METEORITO EM UBATUBA, LITORAL NORTE DE SÃO PAULO
}

\author{
C.R.G.Souzal \& A.P.Souza ${ }^{2}$
}

PALAVRAS-CHAVE: astroblema, geomorfologia, estrutura circular, fotogeologia.

SOUZA, C.R.G.; SOUZA, A.P. (1993) Uma possivel estrutura de impacto de meteorito em Ubatuba, litoral norte de Såo Paulo, Bol.JG-USP, Ser.Cient., 24:21-26.

\section{RESUMO}

Nas últimas décadas, várias crateras de impacto de meteorito têm sido descobertas na superficie terrestre. No Brasil, sảo conhecidas, pelo menos, seis destas estruturas. Este trabalho relata, de maneira preliminar, a ocorrência de uma estrutura circular de $1 \mathrm{~km}$ de diâmetro na região de Ubatuba, supostamente gerada pelo impacto de um meteorito. Algumas caracteristicas geomorfológicas e geológicas da área sugerem esta hipótese: forma aproximadamente circular, anel, em meia-lua, de vertentes rochosas com valores de declividade relativamente altos e proprios do local; desnivel topográfico da área em relação à planicie aluvia. adjacente (Rio Puruba); padrão de drenagem aproximadamente centripeto, associação entre a vegetação nativa c os sedimentos peliticos que recobrem a estrutura.

\section{ABSTRACT}

Various meteoritic impact craters have been discovered on the surface of the Earth in the last few decades. At least six such structures are known in Brazil. This paper briefly describes a possible impact crater ( $1 \mathrm{~km}$ in diameter) in the Ubatuba region, northern seashore of Såo Paulo. Geomorphological and geological characteristics suggestive of a meteoritic impact for this structure include: almost circular shape, half-moon rim with steep slopes; topographic relief relative to adjacent alluvial plain; centripetal drainage pattern; close association between native vegetation and fine sediments that fill the structure.

\section{INTRODUÇÃO}

O termo estruturas de impacto tem sido amplamente utilizado para denominar as estruturas geológicas circulares formadas na superficie terrestre em qualquer tempo geológico, pelo impacto de bólidos celestes das mais variadas dimensōes. Dietz (1961) propôs o termo astroblema, para designar as estruturas mais antigas, ja em fase de erosão profunda, que constituem apenas a cicatriz de uma cratera (do

${ }_{1}^{1}$ Instituto Goológjco, SMA, Såo Paula, Brasil.

2 Departamento de Geologia Geral, Instituto de Geocièncias USP, Sa Paulo, Brasil. 
grego: astro $=$ corpo celeste e blema $=$ cicatriz). De acordo com Khryanina (1979), o diâmetro das estruturas de impacto pode variar de poucos metros a muitas dezenas de quilômetros, segundo o fenômeno envolvido: crateras de impacto de 0,5 a $30 \mathrm{~m}$, e crateras de explosẫo - até $300 \mathrm{~km}$.

Grieve \& Robertson (1979), analisando crateras de impacto encontradas em várias partes do planeta, apresentaram a seguinte classificação: crateras confirmadas (associadas a fragmentos de meteorito), crateras prováveis (com evidências de metamorfismo de choque, mas ausência de fragmentos de meteorito) e crateras possíveis (com algumas evidências físicas compativeis com a origem de impacto, mas ausência definitiva de feições de metamorfismo de choque). Ainda segundo esses autores, as crateras confirmadas apresentam idades entre o Pleistoceno e o Recente; as prováveis, idades entre o Precambriano e o Pleistoceno; e as possiveis, idades inferiores a $600 \mathrm{~m} . \mathrm{a}$.

No Brasil, até a década passada, eram conhecidas seis estruturas associadas ao impacto de meteoritos: Araguainha (GO-MT), Serra da Cangalha (GO), Colônia (SP), São Miguel do Tapuio (PI), Riachão (MA) e Vargeão (SC). Crósta (1982), em sua sintese sobre o conhecimento dessas estruturas, apresenta um resumo das suas principais caracteristicas, citando os trabalhos pioneiros e autores responsáveis pela atribuição de origem de impacto às mesmas

Dentre as seis estruturas brasileiras citadas, apenas nas de Araguainha e Serra da Cangalha foram encontradas evidências de metamorfismo de choque ou impacto: brechas polimiticas com lamelas de choque, feições de deformação por choque e fragmentos de rocha parcialmente fundidos, "cones de estilhaçamento", kink bands em biotita e feldspato, etc. (Mc Hone, 1979, apud Crósta, 1982; Santos \& Mc Hone, 1979; Willige, 1981; Crósta et al., 1981). De acordo com Khryanina (1979), estas evidências são as mais fiéis para a confirmação de origem por impacto de meteorito. Não obstante, em nenhuma das estruturas brasileiras foram encontrados restos de meteoritos.

Conclui-se, portanto, que segundo a classificação de Grieve \& Robertson (1979), as estruturas brasileiras poderiam ser de dois tipos: prováveis (Araguainha e Serra da Cangalha) e possiveis (as demais). De fato, esses autores citam a estrutura de Araguainha, a sétima maior do planeta, como sendo do tipo provável.

\section{LOCALIZACÃo E CARACTERIZA- CÃO MORFOLÓGICA DA ESTRU- TURA}

A estrutura de Ubatuba encontra-se ao fundo da planície costeira do Rio Puruba, encaixada entre este rio e a extremidade norte do Morro do Quiririm (Fig. 1), estando na área do Parque Estadual da Serra do Mar. Apresenta forma aproximadamente circular, com diâmetro médio de $1,1 \mathrm{~km}$ (Fig. 2). Seus limites a norte,

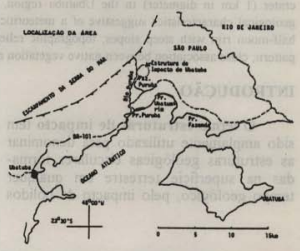

Figura 1 - Localização regional da estrutura circular de Ubatuba (fonte cartográfica: IPT,1981) 


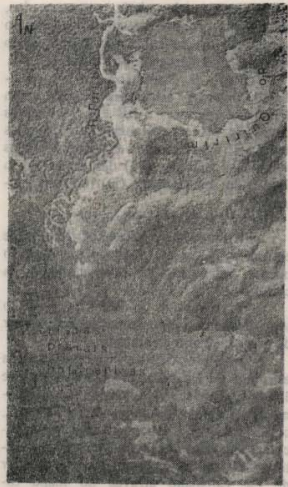

Figura 2 - Retalho de fotografia aérea na escala 1:25.000 (USAF/SGE-1962), com detalhe da estrutura circular de Ubatuba.

leste e sul, são controlados pelas escarpas do embasamento pré-cambriano da Serra do Mar. A oeste, os limites tornam-se pouco distintos em direção à planície aluvial do Rio Puruba (margem esquerda).

Além da forma circular, outras caracteristicas são sugestivas de uma cratera de impacto:

a. padrão semi-circular de vertentes rochosas com valores de declividade relativamente altos e próprios do local, bordejando a estrutura;

b. desnível topográfico da área em relação à planicie do Rio Puruba; c. padrāo aproximadamente centripeto de drenagem;

d. associação entre a vegetação nativa e os sedimentos pelíticos que recobrem a área.

Pela análise de fotografias aéreas de escala 1:25.000, pode-se observar que as vertentes do anel de rochas que circunda a estrutura apresentam-se relativamente mais inclinadas que o padrão regional. Algumas medidas de inclinação efetuadas no anel e em outras vertentes da região, não associadas à estrutura, atestam isto. Essas medidas foram calculadas através dos seguintes passos:

- obtenção das inclinaçôes aparentes ou exageradas das encostas diretamente sobre as fotografias aéreas seguindo o Método do Cartão (Stephens, 1969);

- conversảo dos valores de inclinações aparentes em valores reais, em função da curva de exagero vertical (valor obtido através de cálculo fotogramétrico), utilizando o Ábaco de Conversão de Ray (1960).

Assim, levando-se em consideração a escala real das fotos $(1: 30.000)$ e o exagero vertical $(3,6)$ das mesmas, obteve-se, para - anel, inclinações entre 26 e $32^{\circ}$ (seis medidas). Para o restante da área, os valores variaram entre 6 e $17^{\circ}$ (oito medidas), predominando os de $13^{\circ}$. Uma provável escarpa de falha normal localizada num morrote a sudoeste da estrutura, apresentou inclinação de $72^{\circ}$.

$\mathrm{O}$ desnivel altimétrico, observado no campo, entre a planicie do Rio Puruba e a estrutura, é bem caracterizado ao sul desta, sendo da ordem de $0,7 \mathrm{~m}$. A drenagem, aproximadamente centrípeta, escoa em direção a este setor através de um estreito canal, o qual não apresenta coneç̧ão livre com o Rio Puruba.

A vegetação que recobre a estrutura é densa, constituindo Floresta de Caxeta (Tabebuia sp.), predominantemente. Esta planta é nativa da Mata Atlântica brasileira (vegetação de restinga), somente se desen- 
volvendo sobre substratos argilosos e pantanosos (Alonso, 1977). Com auxilio de um vibrotestemunhador, pesquisadores do Instituto de Geociências da USP (São Paulo), da ORSTOM (França) e do Observatório Nacional (Rio de Janeiro) obtiveram testemunhos com cerca de $8 \mathrm{~m}$ de profundidade no setor sul da estrutura. Embora ainda em fase preliminar de estudos, pôde-se constatar a presença de sedimentos pelítico-arenosos do topo à base dos testemunhos.

\section{ALGUMAS CONSIDERAÇÕES IN- TERPRETATIVAS}

Além da hipótese de impacto de meteorito, quatro outras possibilidades poderiam explicar, a princípio, a origem da estrutura circular:

- colapso cárstico (sinkhole);

- intrusão ígnea circular,

- estruturação dômica do embasamento;

- represamento de um anfiteatro por barramento fluvial (desenvolvimento de uma lagoa, hoje colmatada).

No entanto, de acordo com os dados lito-estruturais regionais e locais disponiveis na literatura (IPT, 1978, 1981), bem como os trabalhos de fotointerpretação geológica e de campo efetuados na área, todas essas outras prováveis causas podem ser descartadas. Não ocorrem, na região, rochas calcárias; o padrão estrutural regional é ENE; intrusōes básicas e/ou alcalinas não foram encontradas na área, sendo o anel formado por biotita-granitos. A hipótese de barramento fluvial explicaria apenas a presença dos sedimentos pelíticos que colmatam a estrutura, mas não o desenvolvimento de um anfiteatro tão circularmente retraído e encaixado ao fundo de uma planície costeira estreita e de fundo de baía. Por outro lado, uma evolução desse anfiteatro a partir de processos morfogenéticos associados às oscilaçōes cli- máticas quaternárias, ainda que acentuados, dificilmente produziriam tal efeito, mesmo porque as caracteristicas morfográficas do anel não coadunam com esta hipótese.

Grieve \& Robertson (1979), estudando diversas estruturas simples com diâmetros inferiores a $3,8 \mathrm{~km}$, em várias partes do planeta, estabeleceram algumas equaçōes relacionando as profundidades real $(\mathrm{Pt})$ e aparente $(\mathrm{Pa})$ das crateras, em função do seu diâmetro (D) (em quilômetros):

$$
\mathrm{Pt}_{\mathrm{t}}=0,326 \cdot \mathrm{D}^{0,786} \text { e } \mathrm{Pa}=0,159 \cdot \mathrm{D}^{0,829}
$$

Pt representa a diferença de altitude entre o topo do anel rochoso e a base do pacote sedimentar de preenchimento da cratera.

$\mathrm{Pa}$ representa a diferença entre o topo do anel e o topo do pacote sedimentar de preenchimento da cratera.

Os valores de Pt e Pa obtidos para a estrutura de Ubatuba, cujo diâmetro é de $1,1 \mathrm{~km}$, são de 350 e $170 \mathrm{~m}$, respectivamente. Assim, a diferença entre $\mathrm{Pt}$ e $\mathrm{Pa}$, correspondente à espessura teórica do pacote sedimentar de preenchimento da cratera, é de $180 \mathrm{~m}$. Note-se bem que o valor de $\mathrm{Pa}$, calculado através do mapa topográfico, é da ordem de $145 \mathrm{~m}$, sendo, portanto, muito próximo ao obtido pela equação

Dence (1972), também através do estudo de diversas crateras conhecidas no mundo, estabeleceu uma classificação com 7 niveis ou graus de preservação da estrutura, baseada na presença e conservação do ejecta e dos produtos de preenchimento da cratera, e no grau de conservação do anel da estrutura: 1. ejecta amplamente preservado; 2. ejecta parcialmente preservado; 3. ejecta removido e anel parcialmente preservado; 4 . anel amplamente erodido e produtos de preenchimento preservados; 5 . produtos de preenchimento da cratera parcialmente preservados; 6 , somente remanescentes dos produtos de 
mente remanescentes dos produtos de preenchimento, com assoalho da cratera já exposto; 7. assoalho da cratera removido e substrato exposto. De acordo com esta classificação, a estrutura de Ubatuba apresenta características dos niveis 3 e 4 , isto é, com ejecta removido (ou soterrado, pois não foram encontrados registros no local), e bordas em anel e produtos de preenchimento da cratera bem preservados.

O estabelecimento de uma idade para o impacto em Ubatuba é ainda bastante prematuro. A estrutura encontra-se na interface planície costeira/Serra do Mar e não há sinais de perturbação na área sedimentar adjacente a ela, seja na planicie aluvial recente do Rio Puruba (a oeste), seja na zona onde afloram cristas praiais holocênicas (ao sul). Sedimentos mais antigos, continentais ou marinhos, não afloram na região, limitando outras correlações mais diretas. Assim, pode-se supor que o impacto teria ocorrido, no minimo, durante o Pleistoceno.

Melosh (1989, p.16-17) relata a ocorrência de uma cratera jovem no deserto do Arizona (EUA), a famosa Meteor Crater, cujo diâmetro é de $1100 \mathrm{~m}$ e a profundidade original, de aproximadamente $150 \mathrm{~m}$. Encontra-se parcialmente preenchida por sedimentos lacustres pleistocênicos e depósitos de encosta holocênicos. A amplitude entre o topo do anel (bem preservado) e a planície ao redor da cratera, formada por rochas paleozóicas horizontalizadas, era originalmente de $67 \mathrm{~m}$, e hoje, após pouca erosão, é de $47 \mathrm{~m}$. As características morfológicas da estrutura de Ubatuba são, a principio, bastante semelhantes as da Meteor Crater. A despeito das diferenciações geológicas e climáticas, ambas podem ter sido geradas na mesma época.

Um outro aspecto a ressaltar, de interesse arqueológico e antropológico, refere-se à existência de ruinas, já parcialmente soterradas, de uma antiga senzala do século XVII (informação de moradores locais) no setor sudeste da estrutura, junto ao Morro do Quiririm.

Finalmente, recomendam-se levantamentos geofisicos e geológicos (evidências petrológicas, Loczy \& Ladeira, 1976, p. 214; estruturais, etc.) mais detalhados, com o objetivo de confirmar as hipóteses aqui levantadas sobre a origem da estrutura e sua espessura. $O$ estudo detalhado dos sedimentos que preenchem a estrutura é também bastante relevante, pois devem conter importantes informações sobre os eventos paleoclimáticos e a evolução cenozóica da região.

\section{REFERÊNCIAS BIBLIOGRÁFICAS}

ALONSO, M.T.A (1977) Vegetação. In: INSTITUTO BRASIEIRO DE GEOGRAFIA E ESTATÍSTICA. Geografia do Brasil: região sudeste. Rio de Janeiro, IBGE. v.3, p.91-118.

CRÓSTA, A.P. (1982) Estruturas de impacto no Brasil: uma sintese do conhecimento atual. In: CONGRESSO BRASILEIRO DE GEOLOGIA, 32., Salvador, 1982. Anais. Salvador, SBG.v.4. p. $1372-1377$.

CRÓSTA, A.P.: GASPAR, J.C., CANDIA, M.A.F. (1981) Feições de metamorfismo de impacto no Domo de Araguainha. Revista Brasileira de Geociências, 11(3): 139-146.

DENCE, RT. (1972) The nature and significance of terrestrial impact structures. In: INTERNATIONAL GEOLOGICAL CONGRESS, 24., Montreal, 1972. Proceedings Montreal, Harpell's Press, 1972. v. 15 , p. 77-89.

DIETZ, R.S. (1961) Astroblemes. Scientific American, 205(2): 141-148

GRIEVE, R.A.F.; ROBERTSON, P.B (1979) The terrestrial cratering record I. Current status of observations. Icarus, 38:212-229. 
INSTITUTO DE PESQUISAS TECNOLÓGICAS (IPT) (1978) Geologia da região administrativa 3, Vale do Paraiba e parte da região administrativa 2 do Estado de São Paulo. (Monografia IPT, 1). São Paulo. 78p.

INSTITUTO DE PESQUISAS TECNOLÓGICAS (IPT) (1981) Mapas Geológico e Geomorfológico do Estado de São Paulo; escala 1:500.000. São Paulo, IPT.

KHRYANINA, L.P. (1979) Meteoritic craters as geologic structures. Geotectonics, 13(3):246-254.

LOCZY, L; LADEIRA, E.A. (1976) Geologia Estrutural e Introdução à Geotectônica. Editora Edgard Blücher, Ltda.

MELOSH, H.J. (1989) Impact Cratering: a Geologic Process. Oxford, Oxford University Press. 245p. (Oxford Monographs on Geology and Geophysics, 11). RAY, R.G. (1960) Aerial photographs in geologic interpretation and mapping. U.S.G.S. Professional Paper, 373.

SANTOS, U.P.; MC HONE, J.F. (1979) Field report on Serra da Cangalha and Riachão circular features. São José dos Campos. 13 p. (Relatório INPE-1458NTE/153).

STEPHENS, E.A. (1969) Structural analysis from air photographs in areas of regionally metamorphosed rocks. Photogrammetria, 25:5-26.

WILLIGE, B.T. (1981) The Araguainha impact structure, central Brazil. Revista Brasileira de Geociências, 11(2):9197.

C.R.G.Souza - Instituto Geológico, Secretaria do Meio Ambiente - Av. Miguel Stefano, 3900, Saúde - CEP 04301-002, Såo Paulo, Brasil.

A.P.Souza - Departamento de Geologia Geral, Instituto de Geociências/USP - Caixa Postal 11.348 - CEP 05422-970, Såo Paulo, Brasil. 